\title{
VISUAL PHENOMENA IN THE DREAMS OF A BLIND SUBJECT
}

\author{
BY RAYMOND H. WHEELER
}

University of Oregon

The subject whose dreams are herein reported was a student at the University of Oregon from 1915-1918. He was a trained introspector and at the time of this investigation he had had several courses in psychology, including laboratory. After a preliminary period of training in recording dreams he found it possible to describe the important details in note form, in American Braille, immediately upon waking. These notes were subsequently edited by the writer with the help of the reagent, great care being taken to omit all uncertain or otherwise questionable details. The reagent lost his sight by accident when eleven years old. $\mathrm{He}$ is now twenty-seven.

Although the primary purpose of this paper is to report visual phenomena in the dream life of a blind subject after sixteen years of blindness, it is interesting to note, in addition, that in his dreams we find a peculiar association between visual images and images in other modalities. In his waking life the subject has very complicated synæsthetic phenomena. It has been noted in the literature ${ }^{1}$ that in certain instances those individuals who possess associations between visual and other sensations in their perceptual processes also associate these modalities in a similar fashion in their imaginal processes. This is also true of our reagent. As far as the writer knows, however, such phenomena in dreams have not been described in the literature. For the convenience of the reader the reagent's descriptions of these associations are printed in italics.

\section{Dream I}

First I had a rather confused visual image of a portion of a room including one large window and the surrounding walls. The light which came through the window

1 To be reported in a subsequent paper. 
was dim, giving the appearance of a heavy fog or thick dust which seemed to fill the room. I could distinctly "see" the rays of light penetrating through the fog. The space in the room, penetrated by the light, seemed to be about six feet wide and three feet doep. Accompanying this oisual imagery zoas a marked unpleasantness, a vivid organic and kinzsthetic experience consisting of a tension in the muscles of $\mathrm{my} \mathrm{arm}$, of a tightening in the vocal cords and of contractions in the muscles of my jaws, the latter resulting in a state of marked rigidity. Then I had a sense of "half pressure and half buzzing" in my ears and a diffuse and vague tension in the muscles of the brows, forehead, neck and chest. The unpleasantness and kinesthetic tensions were linked, in consciousness, with the foggy, yellow light. The second group of experiences constituted an awareness that I was near the walls of the room.

Then I suddenly found myself in a second room in a house some distance away and to the south of the first. Here my imagery was somewhat similar to the preceding but lacking the yellow light and the affective accompaniments. I infer that this house was strange for there was nothing familiar about it. I was then conscious of looking from where I now stood toward the direction of the house I had previously been in. Simultaneously with this change in my line of regard I had a vague flash of strawo-colored light. This meant "south" to me, which I innervated in vocal-motor fashion: "south." (My notion of "south" is associated, in waking consciousness, with straw-colored light.) I then noticed two friends in the room. Both were sitting to my right and a little in front of me. To my left and very near me was localized a very dark mass, somewhat of the size and general shape of a person, with a thick, hazy area as a fainter background. The lines of his shoulders, chest and arms to the elbows were the only distinct features of the figure. Instantly I had the faintest tendency to turn in his direction. This was the first intimation that I had had of being in this house with a companion. I was unable to recognize him for the color of the imagery was too faded. (In waking life I always identify people, in imagery, by their color.)

The friend to my right, seated nearest me was a vague form in sitting position, colored a oery deep shade of blue. The only features which approached distinctness were outlines of his head, arms, legs and trunk. I imagine that the form appeared much the same as a person might look through a thick blue lens with the object much out of focus. The other figure was facon-colored yellow, of medium brightness and rather poor saturation. I identified both of these persons by their colors.

Then there appeared a very irregular image of a large oak chair finished with yellow wood and black leather upholstering. The imagery was localized and distributed in space in a position corresponding to the details of a chair which are visible to the eye when one is sitting. I also had tactual imagery of the "feel" of the upholstering and kinæsthetic imagery of the bodily position assumed in sitting in this style of furniture.

I was then conscious of saying: "Hello boys; when did you get in?" There was no answer. My attention then became more rigidly fixed upon the two visual forms as I thought to myself in verbal imagery: "Why don't they answer?" I then spoke again: "I want you fellows to come over and see me while you are here." Again no answer. I then became very angry; I was conscious of intense tightening of muscles in my arms and chest together with a characteristic tension in the back of my scalp. (This latter is characteristic of anger in waking life.) With the growing anger the colors of the troo forms became very much brighter. I then turned to the figure at my left, which represented my companion, and said: "Let's go back." I then found myself back in the first house but this time in a different room, for the window was on the 
west side and there was a telephone on the wall. The window curtains were streaks of drab-grey, which, I suspect, is my representation of white. The room was large, which I interpret from the fact that I experienced no pressure images. My awareness of the telephone consisted of visual and tactual imagery. I " $\mathrm{saw}$ " the brownish wooden box containing the mechanism of the telephone. In the middle of the transmitter was a circle of rather brilliant light which told me the exact place into which to direct my voice. The hard rubber mouthpiece was visualized as black; the receiver hook was a shining steel-gray as were also the bells. The outlines of these objects were fairly distinct but fleeting. I then had the vocal-motor: "I will call up the boys and ask them over to see me." I had kinæsthetic and tactual imagery of taking down the receiver and of holding it to my ear, with a distinct image of coldness as the edge of the receiver came in contact with my ear. No further imagery appeared until the vocal-motor: "They won't answer," whereupon I was extremely disappointed and angry. Here $I$ had the characteristic sinking experiences localized in the region of the diaphragm, inhibition of breathing and tensions in the throat and chest. I then had the vocal-motor: "You can go straight to the devil." At this moment I became conscious of a person in back of me, visualized as a bright and silvery form, which meant to me that the form was a woman. I then had auditory imagery of her voice: "He has drowned in the creek." Simultaneously with the "he" there appeared a dark visual schema to my right, very indistinct and not sufficiently colored for identification. I next found myself searching for the creek. I was visualizing myself walking up a slope along a winding path. My consciousness of surrounding objects consisted only of kinæsthetic imagery of shrinking, dodging or otherwise avoiding branches, rocks and trees. I was distinctly conscious of an awkwardness with tensions in the trunk, legs, face and shoulders, all of which contributed to an awareness that I was uncertain where to step. I then found myself at a gate. I stepped back and watched a visual image of myself looking over the gate up the hill. Suddenly I lost the "visual me" and was looking at the gate at close quarters. The transition was almost instantaneous. I now visualized the two gate posts distinctly, together with the braces attached to the top of each post. Just beyond the braces was the woven wire, silvery in color, as if it had been galvanized recently. I was then conscious of fingering the wires, at which instant the visual imagery became more distinct. I was aware, next, that just beyond the gate was a hill. I did not visualize the hill distinctly; it was merely a brownish haze-a color which represents rank undergrowth to me; but I was distinctly conscious of tactual and auditory imagery of being in the shadow of a hill. The tactual experiences refer to changes in temperature and the auditory to changes in echo. I retraced my steps down the hill and while on the way noticed a group of oak trees which I had "seen" on my way up. I visualized their peculiar dark brown trunks, knotted and gnarled, and had tactual imagery of running my hand over the bark, covered with moss and lichens. I could see upward as far as the first branches but beyond that the trees faded into a hazy background, thence into nothingness. The brown of the trunks was faded and dim, the color irregular in distribution, giving the effect of a pouring rain on a window pane-a "wiggly" appearance.

At this point in the dream I was conscious of the person who went with me to the second strange house. This consisted of a colored visual scheme at my left, too vague, however, to identify, and also of a peculiar motor "start," characteristic of a sudden consciourness of a person near you. We had a short conversation concerning the oak trees, the details of which I cannot remember. I recall that both his words and mine were in my own verbal imagery. 
I next found myself at the edge of the creek, vividly aware that I was facing the creek and that the first strange house I had entered was back of me. This was present in terms of a faint brownish houe off at the horizon back of me. The water in the creek was sluggish and a dark opaque, oily green. The water almost overran the banks. Next to the edge of the stream I visualized masses of dead, pale, straw-colored grass, most of which was very hazy except for the larger tufts in which latter I seemed to "see" some of the individual blades. The grass lined both banks of the stream and extended over into the water. Suddenly I "saw" a collar and necktie floating down the stream, too far out to be reached. I viewed them indifferently until I had the vocal-motor: "It is $A$ 's collar!" Upon experiencing the verbal imagery I was conscious of intense grief, represented by marked feelings of stuffiness in my chest and by tendencies to sob. I awoke and actually found myself sobbing. Although I did not notice it particularly at the time, I am certain, on recalling the imagery of the collar, that it was white. The tie was blue with large brown bands running diagonally across it. I could not "see" those portions of the objects below the surface of the water.

\section{DREAM 2}

I was seated in a passenger coach, midway between the ends, on the right side of the car and next to the window. I could "see" the vague form and outline of the sunbleached red plush seat directly in front of me. For some little distance in front I could distinguish the yellow woodwork between the windows but farther down the coach the woodwork became very indistinct. A brilliant light was shining through the windows, illuminating the coach. Mixed with the visual images of the plush seats were tactual images of the friction of my trousers as they adhered to the plush, preventing me from making slight movements with ease. I also had clear tactual imagery of my arm as it rested in the sill of the car window.

The objects in the surrounding country were vague and fleeting and seemed to pass by very rapidly. They were of the brightness and tint of vegetation in the sandy desert. Now and then I was conscious of vague outlines of the rolling hills, stretching out in the far distance. I was travelling northeast, indicated to me by a large area of dense blackness which was projected beyond the side of the car off to the front and to the left. This dark or black horizon meant north. The relation of the black schema to the side of the car I interpreted to mean northeast. Then I noticed that my position in the coach had changed. I was riding backward. The dark cloud was now at my back and to my right. I became conscious that my brother was with me. This was in terms of a gray splotch about the size of a man, in sitting position opposite me. My brother said: "We are coming to the Blue Mountains." Although he seemed to be speaking these words, for I was listening in his direction, the words themselves came to me in my own verbal imagery.

Looking out of the window to my left I visualized a range of steep mountains rising abruptly from the desert. Here the brightness of the landscape greatly increased; various vaguely outlined hills passed by the window rapidly; the hills toward the south were dark blue, fading into a dull grey the nearer they were to me. Mixed with the awareness of this blue schema was a tactual image of tall thick grass soaked with rain. As the number of hills increased I was conscious of a distinct feeling of relief, referred to muscular relasations about the brows, eyes and jaws. The thicker the hills became, the more marked became the relief until it merged into wonder and surprise. The muscles of my chest became tense; I was conscious of tendencies to smile. I noticed that on the sides of the nearest hills there were dark patches. Then I vocal- 
ized my brother's words as be spoke again: "The dark places are where they graze their sheep. The dry and sandy places are where the coyotes live." Following these latter words I had fleeting visual images of a comparatively level stretch of ground, covered with innumerable greyish rocks, scattered thickly over a faded, yellowish-brown soil.

\section{DREAM 3}

I was in the middle of a river, astride a log. All about me the water for twenty or thirty feet was jet black and so dense that I could not "see" below the surface. The log was about eight inches in diameter and quite distinctly visualized as an old alder snag which was smooth, with no bark and a very light grey in color. The size of the $\log$ is an interpretation partly from the visual image and partly from the extent to which it protruded out of the water. Its smoothness was present to consciousness partly as an interpretation from the visualized surface and partly from the fact that my legs were adjusted in such fashion as to prevent my slipping on the surface.

I had very distinct motor imagery of balancing myself. This involved my legs, trunk and arms. I judge that I was about one third of the distance back from the front end of the $\log$ which I gather from the manner in which the log responded to my movements. I was going down stream rapidly. This latter consciousness came to me in terms of a visual image of a dark, ribbon-like streamer indicating how the water was being "cut" by the passage of my feet through it. I also had tactual imagery of water rushing rapidly by my hand, an experience similar to the sensations one receives when placing his hands in the water as he rides in a fast boat. Together with this latter visual imagery was auditory imagery of the swishing of the water. I do not know how fast the current was flowing but I seemed to be travelling faster than the stream. I had tactual-kinzsthetic imagery of being hurled rapidly through space in the direction of down-stream.

All about me, especially to the left and in front, small fish, about ten inches long, were continually jumping out of the black, inky water. They leaped only a few inches above the surface, looked at me and disappeared with a croak. I could not visualize the fish clearly but merely got their general shape and size. Sometimes they would appear only on the surface of the water; they would extend their heads upward until their gills appeared when they would utter a peculiar sound and disappear again. In many instances I had auditory imagery of their croaks together with a flash of yellow light, hovering, temporarily, about the region of thetr mouths. In other instances I was aware only of the yellow light, which, however, meant to me that they were making their peculiar sounds. Some of the fish were striped grey and black, the stripes running across their sides from the lower front to the upper back, thus making diagonal bars across their bodies. I was next conscious of the vocal-motor: "These are singing carp." Then I had a visual image of a fish net lying upon the $\log$ in front of me, and the vocalmotor: "I have a net and will get some."

\section{Dream 4}

I was under the south end of a bridge. I was facing the south with the stream in back of me. I have a very distinct remembrance of visualizing the supports of the bridge as I looked through them toward a cloud of yellow light of in the dislance. This cloud of yellow light meant south. I did not visualize the bridge above me but was aware in auditory terms of the faint echo and in tactual terms of the nearness of the bridge to me. I then had visual and kinzsthetic imagery of piling rocks into a gunny sack. I was greatly disturbed both by the fear of getting caught and by my bull- 
dog which kept barking, and pulling vigorously at my trouser's leg. Here the tactual and auditory imagery was profuse and clear. The imagery of the dog's form was indistinct save for a bright straw-colored schema which alvoyys represents this dog to me. I was holding one corner of the sack with my left hand (tactual, motor and visual imagery) and the sack itself was a dark yellowish-brown. I could not "see" the weave and did not notice any tactual imagery of it. Then there appeared the verbal imagery: "I want $A$ to see these before anyone finds me." Then I was vividly aware of the fact that $D$ might find me. This consisted of tenseness about the chest and abdomen, with "sinking sensations" in the region of my stomach. D was represented to me in terms of peculiar flashes of color which corresponded to his ooice. I then awoke.

Three striking peculiarities stand out in the dreams given above. First is the appearance of associations between visual and other sense modalities, which, in every instance conform to synæsthetic phenomena in the reagent's waking life. Schematic forms of persons are identified by color. Persons' voices are recognized by their color; directions of the compass, the "croaking" of the singing carp, the bull dog, are all identified by certain colors. The reagent's auditory imagery is exceedingly deficient both in dream and in waking life but this deficiency is largely compensated for by visual associations or synæsthetic phenomena.

Secondly, our subject has the peculiar tendency to vocalize the spoken words of another person's voice in terms of his own vocal-motor imagery. Colors provide the necessary qualitative differences for identification. This is true both of waking and of dream consciousness. Verbal imagery is very rarely syncopated or abbreviated and is very definite in details of enunciation and of expression.

Thirdly, there is to be noticed a peculiar tendency, in the subject's dreams, to visualize himself at a distance. Various details, which the writer has been able to obtain on this point, indicate that the subject often has a "visual me" in dreams. This "visual me" is evidently a product of repeated tendencies on the part of the subject to visualize himself as he walks about in order to ascertain, if possible, whether he showed his blindness in any peculiarities of walking. This "visual me" appears to him frequently, in dreams, if he is conscious of being watched. The visualized figure consists mostly of hands and feet, separated and in movement as if in walking. Peculiar feeling complexes are associ- 
ated with this visual imagery but otherwise the experiences have not been definitely analyzed. Occasionally this "visual me" appears close to the subject but it is usually localized some distance away.

Visual imagery still outnumbers other modalities both in the subject's dreams and in his waking life. This imagery has now become vague in form and outline. For example, persons lack outlines of eyes, mouth, ears, fingers, and details of trunk and legs. The size and duration of the imagery, however, have remained practically normal. Visual imagery of small objects similarly lacks definiteness but possesses a greater degree of clearness than does visual imagery of larger objects. This is undoubtedly due to the fact that the act of handling small objects makes it easier for the reagent to visualize them. In fact, when the subject wishes to visualize an object clearly he always endeavors to explore it in tactual-motor fashion. In the first dream it will be noticed that as soon as the reagent found himself fingering the wire in the fence, its color increased in vividness and the outlines of the visual imagery became more distinct.

All visual imagery lacks details as well as form and outline. The room visualized in the first dream was devoid of furniture. In like manner were lacking the details of the telephone, the lace curtains, the chair, the scenery along the path, the trees, bushes, clothing, etc. A hill is a mass of color with light and dark patches; mountains are clouds of color; water is lacking in detail of wave or brightness; trees are visualized only in part, and so on.

Taking the place of details in visual imagery are auditoryvocal-motor, tactual and kinæsthetic-organic experiences. For example, the visual imagery of oak trees in dream I is pieced out with tactual imagery of exploring the surface of the trunk. The visual imagery of being seated in a chair is supplemented by tactual imagery. The same is true of talking through a telephone.

Kinæsthetic imagery is exceedingly clear and persistent. In many instances the reagent has hesitated in calling these experiences "images" owing to their vividness, and dis- 
tinctness of localization. Such imagery is very readily recalled. Organic complexes constitute an important feature of our reagent's dreams. While experiencing joy, for instance, he feels the characteristic changes in respiration, the tendencies to smile, and the pleasantness; while in fear he is able to detect the tensions in the throat, the organic changes from the regions of the stomach and diaphragm, and the altered breathing. Again, in anger he is aware of the jaw tensions, the tightness of arms and hands, and the changes in facial expression, all of which seem to be exact copies of experiences in waking life. Organic processes seem to be recalled with greater readiness than visual details.

We believe that the above descriptions demonstrate that the introspective method-at least the terminology-can be applied in the description of dreams. Whereas it may be contended that the chief interest in dreams pertains to their function rather than to their content, it is obvious that the significance of dreams can be much better understood if their content is first described in minute detail. Such descriptions should be obtained by using a method patterned after introspection rather than after interpretation. 